\title{
Key Aspects of Development and Personnel Estimation in the Construction Engineering
}

\author{
Elena Khripko, $^{1, *}$ \\ ${ }^{1}$ Moscow State University of Civil Engineering, Yaroslavskoeshosse, 26, Moscow, 129337, Russia
}

\begin{abstract}
Personnel estimation is the most effective way to get information about the development level of managerial skills in the construction engineering. From economically justifiable assessment tools, used in the practice of personnel management, with regard to the construction industryit's more effectively to combine two tools: assessment center and 360-degree assessment. The use of these assessment tools enables the system research of organizational behavior due to the specifics of business processes is most important in the construction engineering. The complete and maximally objective presentation about the development level of managerial skills for leaders is not only the most important factor in personnel management in the construction engineering, but also how these managerial skills are implemented in organizational behavior as a whole, as the development of managerial competencies in the construction engineering takes into account the system of object relations formed in the organizational environment. The system approach to the heads personnel estimation in the construction engineering can be implemented through the improvement of assessment tools: the use of psychoanalytic approach in the development of content assessment and interpretation of its results.
\end{abstract}

\section{Introduction}

Key aspects of personnel estimation in the construction engineering are based on distinctive industry-specific features. Modern business structures are commonly used for personnel estimation. Personnel estimation is conducted to determine the operating efficiency or to get information about the development level of competencies. The combination of different types of personnel estimation can significantly affect both the personnel management in general and the quality of managerial decision making in particular[1]. However, the selection of assessment tools and the specifics of procedure development and content analysis don't become irrelevant in relation to the construction engineering[2].

Let us consider a step-by-step design evaluation of managerial skills for leaders in the construction industry, the content development for assessment tools, the interpretation of results. The development or realization of competency profiles, the formation of competencies based on the updated model for personnel estimation, the selection of assessment tools, the development of procedure for assessing are related to the stage design[3].

*Corresponding author: geleda@ya.ru 
At the stage of the content development, we should give special consideration to the content of competencies, the level detection of competencies, valuation engagement, indicators determining the development level of managerial skills. The interpretation stage of personnel estimation is particularly important in terms of reflective tendencies of organizational behavior for assessment participants as well as interconnections of individual characteristics, capacities and characteristics of leaders or candidates from the employee pool with systemic manifestations of an organization-wide environment and corporate culture.

It should be noted that implemented different assessment tools for personnel estimation become more informative while using the psychoanalytic approach[4, 5]. The content development of assessment tools and the interpretation of results taking into account the psychoanalytic reconstructions make it possible to assess the quality of object relations and uncondiciousness tendencies of candidates and employees, provide information on latent tendencies of the organizational environment in the construction engineering, which makes it possible to take managerial solutions at a whole new level[6].

The selection of assessment tools is determined primarily by what managerial solutions will be taken on the basis of the obtained results. In general the evaluation is carried out with the aim to plana managerial career for employees and their appointments, create development programs of certain competences and make decisions in the area of employee engagement. Different assessment tools are used for personnel selection. The important hallmark of choosing specific methods is an economic efficiency of using evaluation procedures, namely, how reasonable the expenses on personnel estimation are and what value for construction companies will be the results. Using the psychoanalytic approach when designing or upgrading assessment tools for employees greatly increases the prospects for the use of its results, and therefore, increases the economic efficiency of improved methods. As a basis for upgrading the evaluation of managerial skills in the construction engineering, these two tools Assessment center and 360-degree assessment are the most suitable.

\section{Materials and Methods}

The assessment center is a technology that allows conducting a full assessment of employees by certain competencies. The basis of this assessment tool is the formation of organizational behavior of employees under their professional activities. The assessment center allows you identify the formation degree of personal qualities to successfully carry out their professional duties.

The basis of evaluation procedures is the collection of such information about organizational behavior of leaders that reveals the operating style, abilities, personal qualities and possibilities that should comply with the successful execution of official duties[7]. The factors of successful organizational behavior in the construction engineering are made in the competency profile that is based on designing the tool Assessment center. The assessment center is effective for recruitment. However, this tool is rarely used from the perspective of economic inexpediency.

The 360-degree assessment method was meant to be a way to obtain information about the nature of the employee's activity in his environment, and the application area according to the opinion of the author covers almost the whole field of personnel management. Multiple studies both foreign and local specialists are dedicated to the development, organization and regulation of the evaluation using this method [9]. I should mention the fact that from all the tools except the testing, the 360-degree assessment center is initially most adapted to automation, and now majority of companies use automated versions. 
The point of the 360-degree assessmentis that the information about development level of competencies is collected by asking questions and solving mini cases. Questions and mini cases are addressed to the assessment participant and his environment: colleagues, managers, subordinates. In some cases that are specific to the construction engineering, the list of respondents includes clients and investors. In practice, the personnel management in exceptional situations where there is a need to compile the most comprehensive idea about personality being rated the number of assessment participants includes its immediate surrounding - family members and friends. In practice I can't be able to observe or implement the personnel estimation of local construction companies, however, by reviews of foreign colleagues - the leaders of personnel services -this extension completely eliminates the errors of staff appointments. Of course, this includes the personnel estimation with impeccably developed content. This method has variations, for example, 90 degrees, 180, 360, 540. They are used for a number of reasons which part of the environment covers the evaluation procedure [10].

\section{Results}

The personnel assessment was conducted in 5 construction companies. The number of participants was 620 managers.

The use of the Assessment center in the construction engineering shows that the evaluation findings are used in solving the following universal problems of personnel management:

- Improve the accuracy in detecting thedevelopment level of competencies in accordance with function;

- Development and implementation of training programs and staff development;

- Knowledge management and talent management;

- Designing career paths;

- Formation of an employee pool;

- Improving the efficiency ofrecruitment and staff transition.

The Assessment center is realized in two forms: external and corporate. The external Assessment Center is designed and implemented by specialists who don't have identity in relation to the evaluated business environment, while the corporate one is implemented and realized by services for personnel management of the organization.

To get complete information about the development level of managerial skills, it's better to effectively combine the Assessment center with the 360-degree assessment center. The assessment tools based on this method are used in the world practice of personnel management for almost two decades. For local experts, this method quickly gains popularity after publishing the book by Peter Ward in 2006-the author of the method [8].

The lack of the corporate Assessment center isn't rooted in the content of its content and the quality of the given results. The problem resides in the interpretation of the results (up to $42 \%$ distortion, the data are obtained on the basis of the study results of the Assessment center among 450 leaders of different construction companies). In the course of the performance with the Assessment Centre, $75 \%$ of observers meet the inevitable resistance to detect an insufficient development of competencies, and the results may not be completely used as they inevitably come into conflict with the traditional laws of organization environment in the construction engineering.

By way of illustration how can degrade using the results of the Assessment Center excluding the quality of object relations in the organizational environment, we can give an example from the practice of the headsestimationin one of the construction companies. In this large construction company formed in the divisional departmentation, it was carried out by the corporate assessment center to nominate candidates into the employee pool for 
positions of managers in the divisional departmentation. The evaluation findings revealed a significant lack of development of managerial skills, and therefore the results were below the average, and greatly differed from the planned values laid down in the managers profile (the decrease reached 21\%). The established values into the managers profile showed the desired representation of company executives about middle level senior managers put into the employee pool, and the real figures led to a strong reaction of frustration and search for urgent measures to improve the situation. The solution was found in the fact that one of crucial performance indicators for the next reporting period for the direction of personnel management was to raise the average value of competencyevaluation by $15 \%$. The organizational resistance of this construction company recognizing the development level of managerial skills was so great that the next Assessment center was actually designed to demonstrate the correct numerical result, rather than determine the development of managerial skills of employee pool.

Using the evaluation findings make sense to consider in the non-conventional sense that good results of competency assessment are definitely a positive factor. The assessment participant or the candidate in the employee pool can have highly-developed competencies, but its inconsistency with the quality of object relations in the organizational environment won't contribute to its manifestation in real activity as recorded for $52 \%$ of cases.

\section{Discussion}

The basic idea of the assessment center is to achieve the exact prediction of organizational behavior for assessment participants. The predictability of organizational behavior is very important to resolve issues of personnel managementin the construction engineering due to a superior production lead time in comparison with other industries.

The advantages of the external designing method of the Assessment center for construction companies include the objectivity in evaluation and the independence in interpretation of results. However, it determines the decrease of the evaluation precision as the in-depth study of the features in the organizational environment for the construction company and the specific factors, that influence the success of the organization in this particular environment, will take some time that in turn may be economically unnecessary.

The corporate Assessment center on the contrary can provide more accurate results, as developers and assessment participants are carriers of organizational identity. This method of personnel estimation has more sensitivity with respect to the peculiarities of management processes and organizational behavior in general

For a successful performance of the Assessment center we need to actively involve the identity agents of the organizational environment, but, at the same time, the procedure of results collection and processing require the presence of independent experts for personnel estimation that don't have organizational identity in the construction engineering where will take place the procedure of heads personnel estimation. In this regard, it is fair to say that the success of the Assessment center is to use internal resources and external participation. Consequently, the quality of evaluation findings carried out by using this tool will directly depend on the following main factors, namely:

- what specific goals of personnel estimation are;

- what characteristics of the organizational environment in the construction engineering are;

- how well the competency profile is defined;

- howwell corresponds the performance appraisal modeled in the tool's content to the real successful functioning in specific management levels and positions;

- what level of expert training among observers;

- what character gets in the use of evaluation findings; 
- how well the exact interpretation of the given data will be in the course of the evaluation procedures.

Developers of the Assessment center usually tend to meet the basic requirements for the content of this assessment tool. However, in case of construction companies that's not good enough to admit the use of the evaluation findings highly-efficient. No matter what configuration gets the Assessment center (external or corporate), it's difficult to take into account the features of the organizational environment, and therefore organizational behavior. The features of organizational behavior remain reflective, and in particular this includes the destructive tendencies of organizational behavior. For the heads estimation in the construction engineering it's effectively to use the psychoanalytic approach to study the object relations of organizational behavior in the leader-follower system.

Let's go into the question how the use of the psychoanalytic approach can help reduce organizational resistance and identify disruptive tendencies of organizational behavior. Before designing the content of the Assessment center, it's necessary to run a common diagnosis of the organizational environment and to identify the quality of object relations structuring organizational behavior in general.

The content design of the Assessment center in the construction engineering is based on the necessity to establish analogues of organizational behavior containing the problems of this organizational environment that may be identified during the preliminary stage. The competency profile that is used for personnel estimation should also take into account the best practices of that organizational environment for which is designed and conducted the Assessment center. The design of the Assessment center should be preceded by a diagnostic procedure to identify the problems of management and organizational behavior in general. In this case, it can be more effective to construct focus groups for customers of the Assessment center aimed at the quality research of management and tendencies of organizational behavior. The results of the Assessment center should be discussed not only in the way of feedback with candidates, but it's important to compare them with the tendencies of the organizational environment, and based on these grounds to create development programs of competencies.

Let's analyze how effectively can be implemented the 360-degree assessment tool in the construction engineering and what its resources are. And, first of all, let's consider the training, development and self-development of personnel in the construction engineering. Initially, the emphasis is on the use of feedback as a way to demonstrate the perspectives of assessment participants and directions of its training and development. At this stage, the basis of evaluative questions and case studies may lay the profiled competency profile, and, in case of the high-quality content development, the evaluation findings allow planning educational routes of employees and create staff development programs as a whole. In terms of self-development, the feedback on the evaluation findings can be good at selfanalysis of employees to improve the organizational behavior and determine the selfdevelopment areas of competencies. On the question of training and development, it's necessary to include the evaluation findings of competence development that according to the original idea provide an opportunity to assess the performance level of training or development.

From a psychoanalytic point of view, this way of using the evaluation findings in the construction companies is unjustified. The 360-degree assessment method based on the response of the business (where necessary personal) environment about the activities of assessment participants initially can be highly subjective. Only the content development taking into account the leveling subjectivity of environment responses can provide information that can be effectively used for the competency development and the creation of educational programs.Re-using the tool to get information on the training and development of leaders will inevitably give a distorted picture, as it will bear the impress of 
conflict tendencies, shortcomings in the implementation of management competence, quality of communication, etc. Moreover, the impact of these factors can't be analyzed in terms of using the 360-degree assessment tool, as for assessment participantshey become unreflected aspects of resolution of anxiety and guilt [11].The degree of competence development, the performance evaluation of training outcomes are necessary, in my view, to carry out using other tools like the assessment center, strategy evaluation session, casetesting. If it is possible to make an assessment only by using the 360 -degreeassessment tool, then the content for re-evaluation should be developed from scratch paying attention to the fact that competencies are evaluated by other indicators, inclusively other content evaluation in general, but, at the same time, according to the initial idea, the competency profile must be complete, and the figures are coordinated.

The 360-degree assessment is successfully used for the study of teambuilding. It is believed (primarily, the author of Peter Ward's theory) that using this tool, teambuilding will be more effective as the 360-degree assessmentcan reveal the strengths and weaknesses of the team as a whole by analyzing the feedback of participants.

Based on the practice of personnel estimation in the construction engineering, I consider that for evaluating team members and their team activity this method is counterproductive here. Team building occurs while facilitating the identification of team members with each other [12]. The problem statement of mutual estimation by using the 360-degree assessment tool (or its variations) will inevitably lead to a partial or even complete destruction of the identification processes.

This is due to the unconscious transition of command thinking and command object relations to its individual forms with respect to the organizational behavior and activity, and, thus, the team identity is subject to retrogression. The team activity involves rolebased distribution. For mature teams the role-based distribution can be largely interchangeable. However, the use of the considered assessment tool can initially lead not to the modeled process of individuation [13], but, on the contrary, the creation of such a situation that can involve the diffusion boundaries of the identity and can inevitably reduce the quality of team object relations.

It is to be noted that that the command identification reduces the level of anxiety and unconscious sense of guilt, and the transition during the individual assessment of participants' activity significantly increases both these factors. The structure and quality of teamwork are efficiently and quickly determined by using the case-testing tool in real interaction for estimated group of employees.

Regarding the issue of operating efficiency and effectiveness, the experience has shown that getting reliable results when using the 360-degree tool in this area is impossible. Repeated attempts to make an assessment of the operating efficiency (in particular, management) are observed in those cases when companies use the internal evaluation version developing the content under their own steam. For this purpose, the access to the evaluation findings can be broad, the anonymity that is a prerequisite for using this tool is broken, and this fact can lead to loss of confidence among assessment participants. These evaluation findings don't mean anything, except the attempt to deny the reality of organizational behavior and activity. This is due to the resistance of getting reliable results about operating efficiency. This tool doesn't provide the opportunity to evaluate the achievements of estimated employees, with its help it's possible to analyze the subjective responses of the environment on the degree of competency development that is very important to evaluate the organizational behavior in general. The ability to assess the operating efficiency of certain employees and organizations as a whole provides the Performance appraisal tool. The use of the mentioned tool is subject to the performance management system without the implementation of this valuation type is impossible or impractical. 
The idea to connect the variable component of the salary with the results of the considered assessment tool from the beginning looked very attractive, and totally brought discredit on itself in practice. The use of the evaluation findings in the motivational format results in a significant regression of activities among assessment participants in the general. However, the consistent adjustment of the content with the 360-degree assessment tool allows detect both conscious and implicit (using the psychoanalytic approach) motivators of organizational behavior. The analysis of motivational factors makes it possible to improve the motivation programs for personnel in their nonmonetary component.

The possibilities of the 360-degree method while studying the aspects of organizational behavior are wide enough. I should immediately note these activities for the purpose of which the data of assessment are used incorrectly. Firstly, the use of immediate results isn't effective in making appointments and decisions in the employee pool. The results can be really used for determining the employee's development zones, but designing career paths only on such a basis is groundless. The 360-degree assessment records the opinion of employee's environment about his competency development in real time. It's not possible to measure potential abilities and abilities of employees using this tool.

Powerful capabilities are open when using the results of the considered assessment tool to analyze the quality of internal and external communications, as well as the psychological climate of individual units or companies as a whole. Only the study evaluating the resistance provides valuable information on the analysis of the organizational environment. I use this assessment tool to diagnose the organizational environment and determine the quality of object relations. The psychoanalytic interpretation of the evaluation findings reveal hidden conflict tendencies, allows us identify hidden, unelected organizational problems both individuals and groups in the construction engineering. The achievement of the results on latent tendencies and contradictions that distort the managerial function is based on the fact that many specialists believe the lack of this method, namely, on the subjectivity of responses among assessment participants.

Using this method with the psychoanalytic approach to develop the evaluation content (questionnaires and mini case studies), it is possible to obtain information about the number of employees or a certain level of management perceives the organizational environment as hostile or friendly, anxious, conflict, destructive or creative, etc.

The 360-degree tool is invaluable while identifying the sources of anxiety and guilt. The information about the state of balance evaluation and self-appraisal reveals not only the fact what the employees' self-esteem is in comparison with the evaluation of its environment, the configuration analysis of self-appraisal for organizations as a whole gives an idea of the quality of management [14]. For example, the high-positive difference (from one point and more) between the employees' self-esteem and his evaluation of the environments associated with the degree of reflexive destructive reacting in managerial decision making. Including the evaluation as the colleagues environment from other departments allows us analyze the quality of business object relations and formed on their basis of communication between various departments that are related with common tasks.

The fact that employees find it difficult or refuse to characterize their colleagues from other departments (providing, if getting this information was built in the tool development) shows the destructive competitive manifestations in the team of top managers and chief executives of the company.

As an example of upgrading the 360-degree assessment tool, I will give one of the methods developed to detect the quality of object relations and diagnostics of the organization environment. If in case of semantic identity the outline of content elements offers assessment participants the choice of options complied taking into account three main types of object relations, the outcome analysis of the statistics will determine the quality of object relations and interpret them to a high precision. Then it becomes possible 
to deploy resources of the method in personnel appointments and recruitment. There are high chances that we can predict the main patterns of organizational behavior of a staff member depending on the environment where he works or where he will work.

The estimation resource by the 360-degree method still involves the fact that it can positively influence the development of the organizational environment through the formation of the feedback culture. The assessment procedure involves a structured way to provide feedback. The development of the organizational environment, from the psychoanalytic point of view, is, first of all, in the progression of object relations and in gaining the quality of object constancy, mature forms of identity, and the repertoire of the best group defense mechanisms for this type of activity. The 360-degree assessment with its proper use promotes forming mature forms of internal interactive communications, the development of the reflective function, and the ability for self-analysis. Thus, the assessment tool may become one of the tools for designing the corporate dialogue and the dissemination of best practices for that dialogue in the organizational environment as a whole.

\section{Conclusion}

In practice you can meet different options for technology transfer; external contractors develop the assessment tool as requested by the organization, and then send materials and provide management training. However, to evaluate managerial skills of leaders in the construction engineering, it's effectively to use the combined version, specifically:

- the realization and selection of competencies for personnel estimation carried out by external moderation of focus groups featuring leaders of functional areas;

- the evaluation is organized and conducted by external experts with the participation of observers and experts - company executives that have the specific training;

- the processing and interpretation of the results is carried out by external experts for personnel estimation;

- the providing and discussing of evaluation findings is made in the format of focus groups of key executives.

Before carrying out the assessment center in the construction company, it's necessary to run diagnostics of the organizational environment and identify the quality of object relations structuring the organizational behavior in general. This task was successfully implemented using the 360-degree assessment tool. As a result, the use of two assessment tools (the assessment center and the 360-degree assessment) fully shows the development level of managerial skills in the construction engineering. The assessment center should be designed taking into account the actual patterns of organizational behavior, correlates of real managerial situations that exist in the building company.

The modeling or realization of competences by which chief executives are evaluated should be premised on the best practices of the specific organizational environment. Selecting the best practices, focus groups with senior executives are the most effective as they are aimed at the research quality management and tendencies of organizational behavior. The evaluation findings of leaders in the construction engineering compare with the problems of developing the organizational environment, and on this basis form the development plan of competencies. The combination of the tools Assessment Centre and 360-degree assessment allows perform diagnosis of problems in the organizational environment effectively implementing the system approach to the study and further development of the organizational behavior in the construction engineering. 


\section{References}

1. E.A.Shnyrenkov, I.P. Pryadko, Procedia Engineering, 117 (2015)

2. E.V. Romanova, Economic and tourism, 73-80 (2016)

3. N.G.Miloradova, A.D. Ishkov, MatecWeb Conference73, 07003 (2016)

4. A. Sant'Anna, International Forum of Psychoanalysis21, 1 (2012)

5. O.F.Kernberg, R.Michels, Journal of the American Psychoanalytic Association64, 3(2016)

6. E.Khripko, Matec web of conferences73, 07021 (2016)

7. A.D.Ishkov, N.G.Miloradova, A.Yu.Chernyshev, Procedia, 171(2015)

8. P.Atkins, R.Wood, Personnel Psychology 55, 4 (2002)

9. J.W.Smither, R.R. Reilly, Personnel Psychology, 58 (2005)

10. R.Eichinger, Perspectives, 27 (2004)

11. E.Khripko, SGEM-2016, 1 (2016)

12. M.Bohlouli, N.Mittas, G.Kakarontzas, T.Theodosiou, L. Angelis, M.Fathi, A mathematical approach Expert Systems with Applications 70, 15 (2017)

13. U.P.Kanning, Organisationspsychologie 61, 1 (2017)

14. W. Bent, The Foreign Service Journal, 9 (2015) 